\title{
Gerardo Moreno, MD, MSHS, Selected as 2015 NAM Puffer/ABFM Fellow
}

\section{Jane Ireland}

The National Academy of Medicine (NAM) has selected Gerardo Moreno, MD, MSHS, as the 2015 James C. Puffer, MD/American Board of Family Medicine (ABFM) Fellow. Dr. Moreno is an assistant professor in the Department of Family Medicine at the University of California, Los Angeles (UCLA). He is 1 of 5 outstanding health professionals selected for the class of 2015 NAM anniversary fellows.

Dr. Moreno received his medical degree from UCLA and completed his postdoctoral clinical resi-

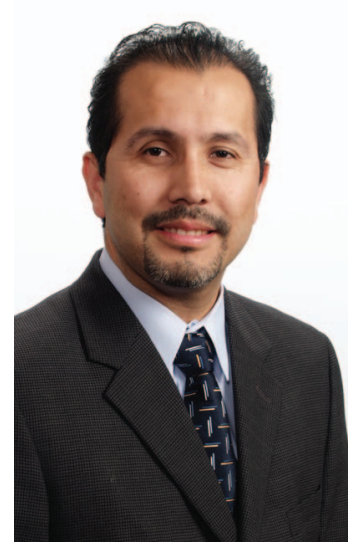
dency training in family medicine at the University of California, San Francisco. He received a master of science degree in Health Services from the UCLA School of Public Health and completed a postdoctoral research fellowship in the Robert Wood Johnson Foundation Clinical Scholars Program at UCLA.

Dr. Moreno's research interests include minority aging, health and health care disparities, and physician workforce diversity. He is a federally funded clinician investigator with formal training and expertise in community-based participatory research and health services outcomes research. He is a recipient of a National Institute on Aging Paul B.

Conflict of interest: The author is the communications editor for the ABFM.
Beeson Career Development Award in Aging (K23). Dr. Moreno chairs UCLA's oversight committee for the implementation of the School of Medicine's Diversity Strategic Plan and is a member of the steering committee for community engagement for the UCLA School of Medicine and Health System. He also co-directs the Community Liaison Core for the National Institutes of Health/ National Institute on Aging-funded UCLA Resource Center for Minority Aging Research/Center for Health Improvement for Minority Elders. Dr. Moreno is codirector of the UCLA MyMeds program and is co-principle investigator for the evaluation of this patient-centered medical home practice-based clinical pharmacist and health information technology medication management program in 28 practices.

As a Puffer/ABFM/NAM anniversary fellow, Dr. Moreno will receive a research stipend of $\$ 25,000$. Named in honor of James C. Puffer, MD, president and chief executive officer of the ABFM, the fellowship program enables talented, early career health policy and science scholars in family medicine to participate in the work of the academies and further their careers as future leaders in the field.

NAM anniversary fellows continue their main responsibilities while engaging part time, over a 2-year period, in the academies' health and science policy work. A committee appointed by the president of the Institute of Medicine selects fellows based on their professional accomplishments, their potential for leadership in health policy in the field of family medicine, their reputation as scholars, and the relevance of their expertise to the work of NAM and the Institute of Medicine. 